HR 0,83[IC 95\% 0,76-0,90]) and gender ( $\mathrm{p}=4,36 \times 10-2$, HR 1,66[IC 95\% 1,01$2,72]$ ) were associated to discontinuation due to remission.

Conclusions: Our results show that different sets of clinical and demographical variables are significantly associated to biological therapy survival depending on the discontinuation cause.

Disclosure of Interest: None declared

DOI: 10.1136/annrheumdis-2018-eular.6109

\section{AB0454 BIOLOGICAL THERAPIES SURVIVAL IN ADULTS AND JUVENILE ONSET ARTHRITIS. DATA FROM BIOBADAGUAY REGISTRY}

M.G. Avila-Pedrettii ${ }^{1}$, Z. Morel ${ }^{1}$, N. Cabrera ${ }^{2}$, S. Cabrera-Villalba ${ }^{1}$, I. Acosta Colman $^{1}$, P. Babak 1 , P. Melgarejo ${ }^{1}$, G. Elizaur ${ }^{1}$, M. Franco ${ }^{1}$, P. Delgadillo ${ }^{1}$ D. Cordovilla Montero ${ }^{3}$, J. Losanto ${ }^{4}$, L. Roman ${ }^{4}$, E. Paredes ${ }^{1}$, J. Mazzoleni' ${ }^{1}$, P. de Abreu ${ }^{2}$, on behalf of BIOBADAGUAY. ${ }^{1}$ Rheumatology, Hospital Central del Instituto de Previsión Social; ${ }^{2}$ Rheumatology, Sociedad Paraguaya de Reumatología, Asunción, Paraguay; ${ }^{3}$ Rheumatology, Insituto Nacional de Reumatología, Montevideo, Uruguay; ${ }^{4}$ Rheumatology, Hospital de Clínicas, Asunción, Paraguay

Background: Survival of biological therapies (BT) may be considered as an indicator of efficacy and safety of the drug. BT survival have been studied mainly in adult's patients, whereas only few studies have been focused on paediatric population to date.

Objectives: To analyse and compare BT survival in adults and juvenile onset arthritis patients from BIOBADAGUAY registry.

Methods: Patients with a chronic inflammatory arthritis enrolled in the Paraguayan-Uruguayan biological register (BIOBADAGUAY) between2015 and 2017 where included. For this study, patients were divided in two groups: 1 . Adults with anychronic inflammatory arthritis and 2. Patients with juvenile idiopathic arthritis (JIA). To compare the groups according to BT, only the first biotherapy was considered.

Survival analysis was performed using Kaplan-Meier estimators and proportional hazard regression model. First we analysed global BT survival in both groups; secondly we compare BT survival between groups.

Results: From 778 BTs(etanercept $n=184$, adalimumab $n=440$, rituximab $n=44$, infliximab $n=27$, tocilizumab $n=75$, and others $n=8$ ), 556 where identify as first line BTs. Of these, only adalimumab and etanercept were included in the study due to sufficient number prescriptions in both groups for the analysis.

We found a mean survival times for adults of 289 ( \pm 20.7 SD) weeks for etanercept and 287 ( $\pm 8.6 \mathrm{SD}$ ) weeks for adalimumab. In JIA patients the mean survival were $243( \pm 26.0 \mathrm{SD})$ and $216( \pm 24.0 \mathrm{SD})$ weeks for etanercept and adalimumab respectively

When comparing survival between groups, we found that JIA presented more discontinuation of BT when compare with adult patients $(\mathrm{p}=4.4 \times 10-4, \mathrm{HR}=0.51$ $[95 \% \mathrm{Cl}, 0.35-0.73])$. Similar results were observed when analysing only etanercept $(\mathrm{p}=3.92 \times 10-2 ; \mathrm{HR}=0.50$ [95\% Cl, 0.26-0.97]) or adalimumab $(\mathrm{p}=1.20 \times 10-$ 3; $\mathrm{HR}=0.48[95 \% \mathrm{Cl}, 0.30-0.75])$ treatments. Then we analysed withdrawn motive in JIA patients, and found that remission was the principal reason of discontinuation in this group of patients.

Finally, we stratified survival analysis by discontinuation according to adverse events, and found that JIA group presented a lower risk of discontinuation due to adverse events than adults $(p=1.96 \times 10-1 ; \mathrm{HR}=2.18[95 \% \mathrm{Cl}, 0.67-7.07])$.

Conclusions: In our study we have analysed mean BT survival between adults and JIA at the BIOBADAGUAY registry. When we compared both groups of patients it was observed that JIA patients presented more BT discontinuation but due to remission.

Disclosure of Interest: None declared

DOI: 10.1136/annrheumdis-2018-eular.6652

\section{AB0455 IMPACT OF ONE-YEAR TREATMENT WITH BIOTECHNOLOGIC DRUGS ON WORK DISABILITY AND ACTIVITY IMPAIRMENT IN PATIENTS WITH RHEUMATOID ARTHRITIS}

M. Manara ${ }^{1}$, R. Caporali ${ }^{2}$, R. Gorla ${ }^{3}$, E. Fusaro ${ }^{4}$, R. Pellerito ${ }^{5}$, P.A. Rocchetta ${ }^{6}$, P. Sarzi Puttini ${ }^{7}$, S. Capri ${ }^{8}$, L. Sinigaglia ${ }^{1} .{ }^{1}$ Gaetano Pini Institute, Milan; ${ }^{2}$ University of Pavia, IRCCS Policlinico San Matteo Foundation, Pavia; ${ }^{3}$ Spedali Civili, Brescia; ${ }^{4}$ Città della Salute e della Scienza; ${ }^{5}$ Ospedale Mauriziano, Torino; ${ }^{6}$ ASO SS. Antonio e Biagio e C. Arrigo, Alessandria; ${ }^{7}$ L. Sacco Hospital, Milan; ${ }^{8}$ School of Economics and Management, LIUC University, Castellanza, Italy

Background: Disease activity significantly impacts on work ability of patients with Rheumatoid Arthritis (RA). Biologic agents can control disease activity, but their effects on productivity outcomes were not adequately investigated in Italian population
Objectives: Aim of the study was to evaluate the impact of biologic therapy on work productivity outcomes in a cohort of biologic-naïve patients with active RA from northern Italy.

Methods: This is a multicentre prospective study on patients with active RA in working age (18-65 years), scheduled to undergo their first biologic treatment. Demographics and clinical data were collected at baseline and at 6 and 12 months, together with productivity outcomes assessed with the RA-specific work productivity survey (WPS-RA) ${ }^{1}$ and the Health and Labour Questionnaire (HLQ) ${ }^{2}$. Primary outcome was the productivity loss or gain after 1 year of treatment.

Results: We included 100 patients from 7 rheumatology centres in northern Italy with active RA [mean DAS28: 5,1 (SD 0,9), median SDAl: 25,2 (IQR 18,7-33,2)]. Most of them were females $(85 \%)$, with a mean age of 49,1 (SD: 10,3$)$ years and a median disease duration of 7 (IQR: $3-14$ ) years. Patients were treated with TNFinhibitors $(68 \%)$, Abatacept $(24 \%)$ or Tocilizumab $(8 \%)$. At baseline 39 patients were unemployed. After 1 year of treatment, 85 patients were still on follow-up, with an improvement in all indexes of disease activity [mean DAS28: 2,8 (SD 1,3), median SDAl: 5,1 (IQR 1,9-12,9)]. A significant reduction in number of days of work missed (absenteeism) and of reduced productivity (presenteeism) was observed in employed subjects, as well as a significant decrease in number of days missed of household work and social activities in all the study population (table 1).

\section{Abstract AB0455 - Table 1}

\begin{tabular}{|c|c|c|c|}
\hline & $\begin{array}{c}\text { Baseline } \\
\text { [mean } \\
\text { (SD)] }\end{array}$ & $\begin{array}{l}12 \text { months } \\
\text { [mean } \\
\text { (SD)] }\end{array}$ & $\begin{array}{c}p \\
\text { (t-test for } \\
\text { paired data) }\end{array}$ \\
\hline Number of days of work missed (absenteism) & $2.5(3.6)$ & $0.5(1.3)$ & 0.003 \\
\hline $\begin{array}{l}\text { Number of days of reduced productivity } \\
\text { (presenteism) }\end{array}$ & $6.7(7.9)$ & $0.7(1.6)$ & 0.000 \\
\hline $\begin{array}{l}\text { Rate of arthritis interference with work } \\
\text { productivity ( } 0-10 \text { points scale) }\end{array}$ & $3.8(3.6)$ & $1.3(2.1)$ & 0.014 \\
\hline Number of days of household work missed & $7.5(8.9)$ & $3.2(6.2)$ & 0.000 \\
\hline $\begin{array}{l}\text { Number of days of reduced productivity in } \\
\text { household work }\end{array}$ & $8.9(9.6)$ & $2.9(5.3)$ & 0.000 \\
\hline Number of days with social activities missed & $6.8(9.3)$ & $1.9(4.8)$ & 0.000 \\
\hline Number of days with need for outside help & $5.5(8.2)$ & $1.5(4.6)$ & 0.000 \\
\hline $\begin{array}{l}\text { Rate of arthritis interference with household } \\
\text { work productivity (0-10 points scale) }\end{array}$ & $6.1(2.8)$ & $3.1(3)$ & 0.000 \\
\hline
\end{tabular}

Conclusions: One year of treatment with biological drugs was associated with a significant improvement in outcomes related to productivity both within and outside home in a cohort of patients with RA.

\section{REFERENCES :}

[1] Osterhaus JT. Arthritis Res Ther. 2009;11:R73.

[2] Van Roijen L. Int J Technol Assess Health Care 1996;12:405-15.

Disclosure of Interest: M. Manara: None declared, R. Caporali: None declared R. Gorla: None declared, E. Fusaro: None declared, R. Pellerito: None declared P. A. Rocchetta: None declared, P. Sarzi Puttini: None declared, S. Capri Consultant for: Pfizer, L. Sinigaglia: None declared DOI: 10.1136/annrheumdis-2018-eular.5279

\section{AB0456 EFFICACY AND SAFETY OF SWITCHING FROM ETANERCEPT REFERENCE PRODUCT TO LBEC0101 (ETANERCEPT BIOSIMILAR) COMPARED WITH CONTINUING LBEC0101 IN PATIENTS WITH RHEUMATOID ARTHRITIS}

Y.W. Song ${ }^{1}$, H. Matsuno ${ }^{2,3}$, M.-C. Park ${ }^{4}$, M. Tomomitsu ${ }^{5}$, S. Shin ${ }^{6}$, J. Lee ${ }^{6}$, on behalf of LBEC0101 Research Group. ' ${ }^{1}$ Seoul National University Hospital, Seoul, Korea, Republic of Ireland; ${ }^{2}$ Tokyo Medical University, Tokyo; ${ }^{3}$ Matsuno Clinic for Rheumatic Diseases, Toyama, Japan; ${ }^{4}$ Division of Rheumatology, Yonsei University College of Medicine, Seoul, Korea, Republic of Ireland; ${ }^{5}$ Mochida Pharmaceutical Co., Ltd, Tokyo, Japan; ${ }^{6}$ LG CHEM, Seoul, Korea, Republic of Ireland

Background: LBEC0101 is a newly developed biosimilar of etanercept (ETN) As rheumatoid arthritis (RA) treatment is a long-standing process in the clinical practice, the long-term safety and efficacy of anti-TNF inhibitors have been studied and reported. ${ }^{1}$ Clinical studies have been conducted to evaluate the efficacy and safety of biosimilar after switching from their originator drug. ${ }^{2}$

Objectives: To evaluate the long-term efficacy, safety, and immunogenicity of switching from the ETN reference product (RP) to LBEC0101 or continuing LBEC0101 in patients with RA.

Methods: This multicenter, single-arm, open-label extension study enrolled patients with RA who had completed the 52 week treatment period of the 